\title{
Use of the Pipeline embolization device in the treatment of iatrogenic intracranial vascular injuries: a bi-institutional experience
}

\author{
Julius Griauzde, MD, ${ }^{1}$ Vijay M. Ravindra, MD, MSPH, ${ }^{2}$ Neeraj Chaudhary, MD, ${ }^{1,3}$ \\ Joseph J. Gemmete, MD, ${ }^{1,3,4}$ Marcus D. Mazur, MD, ${ }^{2}$ Christopher D. Roark, MD, ${ }^{5}$ \\ William T. Couldwell, MD, PhD, ${ }^{2}$ Min S. Park, MD, ${ }^{2}$ Philipp Taussky, MD, ${ }^{2}$ and \\ Aditya S. Pandey, MD1,3
}

Departments of ${ }^{1}$ Radiology, ${ }^{3}$ Neurosurgery, and ${ }^{4}$ Otolaryngology, University of Michigan Health System, Ann Arbor, Michigan; ${ }^{2}$ Department of Neurosurgery, University of Utah School of Medicine, Salt Lake City, Utah; and ${ }^{5}$ Department of Neurosurgery, University of Colorado Anschutz Medical Campus, Aurora, Colorado

OBJECTIVE Flow-diverting devices have been used for the treatment of complex intracranial vascular pathology with success, but the role of these devices in treating iatrogenic intracranial vascular injuries has yet to be clearly defined. Here, the authors report their bi-institutional experience with the use of the Pipeline embolization device (PED) for the treatment of iatrogenic intracranial vascular injuries.

METHODS The authors reviewed a retrospective cohort of patients with iatrogenic injuries to the intracranial vasculature that were treated with the PED between 2012 and 2016. Data collection included demographic data, indications for treatment, number and sizes of PEDs used, and immediate and follow-up angiographic and clinical outcomes.

RESULTS Four patients with a mean age of 47.5 years (range 18-63 years) underwent PED placement for iatrogenic vessel injuries. In 3 patients, the intracranial internal carotid artery (ICA) was injured during transnasal tumor resection. In 1 patient, a basilar apex injury occurred during endoscopic third ventriculostomy. Three patients had a pseudoaneurysm as a result of vessel injury, and 1 patient had frank ICA laceration and extravasation. All 3 pseudoaneurysms were successfully treated with PED deployment. The ICA laceration was refractory to PED placement, and the vessel was subsequently occluded endovascularly. All 4 patients had a good clinical outcome (modified Rankin Scale score of 0 or 1).

CONCLUSIONS The use of the PED is feasible in the management of iatrogenic pseudoaneurysms of the intracranial vasculature. In cases of frank vessel perforation, an alternative strategy such as covered stent placement should be considered. Endovascular or surgical vessel occlusion remains the definitive treatment in cases of refractory hemorrhage. https://thejns.org/doi/abs/10.3171/2017.3.FOCUS1735

KEY WORDS Pipeline embolization device; pseudoaneurysm; vessel injury; iatrogenic

I NTRACRANIAL vessel injury is a dire complication of neurosurgical procedures that presents a significant challenge to the treating physician. The vessel injury commonly manifests as frank vessel disruption leading to a traumatic aneurysm and extravasation of blood or a partial vascular wall injury leading to pseudoaneurysm formation. ${ }^{4}$ Various endovascular techniques have been used in the treatment of iatrogenic intracranial vessel injuries, including coil embolization, stent-assisted coil embolization, covered stent placement, and the use of liquid embolic agents. ${ }^{4,711}$ As experience with flow-diverting stents has increased, their use has expanded greatly beyond the wide-necked intracranial internal carotid artery (ICA) aneurysms for which they were initially intended. ${ }^{3,20,21}$ Flow-diverting stents act as physical barriers, decreasing the velocity and pressure of intraaneurysmal blood flow

ABBREVIATIONS ICA = internal carotid artery; $m R S=$ modified Rankin Scale; $P E D=$ Pipeline embolization device 
and promoting thrombosis. ${ }^{6}$ Additionally, they provide a scaffolding for long-term endothelialization across an aneurysm neck, effectively excluding the aneurysm from the circulation. ${ }^{6}$ The Pipeline embolization device (PED, Medtronic) is the only flow-diversion device that is approved by the FDA for use in the United States. In this paper, we present our bi-institutional experience with the use of the PED in the treatment of iatrogenic injuries of the intracranial vasculature.

\section{Methods \\ Study Design}

This was a retrospective study of cases from the University of Michigan Health System in Ann Arbor, Michigan, and the University of Utah Hospital in Salt Lake City, Utah. Institutional review board approval was obtained at each participating center.

\section{Patient Population and Data}

Procedural logs were screened for use of a PED in the treatment of iatrogenic intracranial vascular injuries between January 2012 and December 2016. Patient demographic data, indications for treatment, operative reports, radiological images, endovascular procedure notes, and the patients' postprocedure hospital course were reviewed. Procedural data evaluated included number of procedures, number of PEDs used, size of PED(s) used, procedural complications, and immediate postprocedural angiographic outcome. Postprocedural data evaluated included postoperative hospital course, modified Rankin scale (mRS) score, significant neurological events, and follow-up procedures and angiography.

\section{Endovascular Techniques}

Informed consent was obtained from the patient or legal representative for the use of a PED for the treatment of intracranial vessel injury, which is an off-label use. Immediate postsurgical cerebral angiography was performed after intraoperative vessel injury. The affected vascular distribution was evaluated first, followed by assessment of collateral vasculature, in case vessel occlusion might be needed. If an acute vascular injury was identified, intervention proceeded immediately. In cases without evidence of vessel injury on immediate angiography, the patient was admitted to the neurosurgical intensive care unit and monitored closely with a plan for short-term follow-up angiography within 2 weeks. If patients were medically and neurologically stable, they were moved to the general care floor.
For placement of the PED, the diagnostic catheter was exchanged over an exchange-length wire for a 6-Fr Cook shuttle sheath (Cook Medical) and a Navien guide catheter (0.058 $\mathrm{mm}$ or $0.072 \mathrm{~mm}$; Medtronic). Next, roadmap angiography was performed, and a Marksman microcatheter (Medtronic) was advanced over a microwire through the Navien guide catheter beyond the vessel injury. A PED was then deployed across the area of injury. In cases in which a PED was used as the primary treatment for vessel injury, patients were not administered antiplatelet agents prior to the procedure. In these cases, patients were administered $10 \mathrm{mg}$ of abciximab intravenously immediately prior to PED deployment and a second dose of $10 \mathrm{mg} \mathrm{im-}$ mediately after deployment. Patients were then started on prasugrel and aspirin. They were maintained on prasugrel for 6 months and aspirin indefinitely; prasugrel was used in these cases because of the interference of the administered abciximab with P2Y12 testing. In cases in which PED treatment was used for a recurrent lesion, patients being treated with clopidogrel and aspirin were confirmed to have achieved a therapeutic response to the medications prior to the procedure. Clopidogrel was continued for 6 months and aspirin was continued indefinitely. Follow-up angiographic imaging (MR angiography, CT angiography, or digital subtraction angiography) was performed at 3-6 months after PED placement and then at the treating physician's discretion.

\section{Results}

The patient population included 3 women and 1 man with an average age of 47.5 years (range $18-63$ years). In 3 patients, the intracranial ICA was injured during transnasal tumor resection (1 pituitary macroadenoma, 1 recurrent pituitary macroadenoma, and 1 recurrent chordoma invading the sella). In 1 patient, a basilar apex injury occurred during attempted endoscopic ventriculostomy after biopsy of a pineal parenchymal tumor. Three patients underwent immediate postsurgical angiography. Immediate angiography was negative in 2 cases, and active contrast extravasation was seen in 1 case. One patient was transferred from an outside institution with confirmed ICA injury from transsphenoidal pituitary tumor resection 19 days earlier. The preprocedural patient characteristics are summarized in Table 1.

Three patients had pseudoaneurysms at the site of vessel injury, and 1 patient had a complete vessel laceration. Three patients underwent primary treatment of their vessel injury with PED. One patient had a recurrent pseudoaneurysm (initially treated with stent-assisted coiling),

\section{TABLE 1. Patient characteristics}

\begin{tabular}{|c|c|c|c|c|c|}
\hline Case No. & Age (yrs), Sex & Tumor Type & Surgery & Artery Injured & Initial Angiogram \\
\hline 1 & $18, F$ & Pineal parenchymal tumor & Endoscopic biopsy \& ventriculostomy & BA & Negative \\
\hline 2 & $49, F$ & Recurrent chordoma & Transnasal resection & ICA & Negative \\
\hline 3 & $63, F$ & Recurrent pituitary macroadenoma & TSRPT & ICA & Vessel laceration \\
\hline 4 & $60, \mathrm{M}$ & Pituitary macroadenoma & TSRPT & ICA & - \\
\hline
\end{tabular}

$\mathrm{BA}=$ basilar artery; $\mathrm{TSRPT}=$ transsphenoidal resection of pituitary tumor; $-=$ not available. 
TABLE 2. Procedural and outcome details

\begin{tabular}{|c|c|c|c|c|c|c|c|c|}
\hline $\begin{array}{l}\text { Case } \\
\text { No. }\end{array}$ & $\begin{array}{l}\text { Vessel } \\
\text { Injury }\end{array}$ & $\begin{array}{l}\text { Initial } \\
\text { Treatment }\end{array}$ & Initial Outcome & $\begin{array}{l}\text { Additional } \\
\text { Treatment }\end{array}$ & $\begin{array}{l}\text { No. of PEDs Used } \\
\text { \& Size }(\mathrm{mm})\end{array}$ & $\begin{array}{c}\text { PED } \\
\text { Successful }\end{array}$ & Follow-Up Imaging & $\begin{array}{l}\mathrm{mRS} \\
\text { Score }\end{array}$ \\
\hline 1 & Basilar PS & $\begin{array}{l}\text { LVIS Jr. stent } \\
\quad+\text { coils }\end{array}$ & Recurrent PS & PED + coils & 1 PED: $2.75 \times 14$ & Yes & $\begin{array}{l}\text { DSA showing no recur- } \\
\text { rence at } 4 \& 12 \text { mos }\end{array}$ & 0 \\
\hline 2 & ICA PS & PED & No residual PS & NA & $\begin{array}{l}2 \text { PEDs: } 4 \times 25 \& \\
\quad 4.25 \times 16\end{array}$ & Yes & $\begin{array}{l}\text { CTA showing no recur- } \\
\text { rence at } 6 \text { mos }\end{array}$ & 0 \\
\hline 3 & $\begin{array}{l}\text { ICA extrava- } \\
\text { sation }\end{array}$ & PED & $\begin{array}{c}\text { Persistent contrast } \\
\text { extravasation }\end{array}$ & Vessel occlusion & 1 PED: $5 \times 35$ & No & NA & 1 \\
\hline 4 & ICA PS & PED & No residual PS & NA & 1 PED: $4.5 \times 20$ & Yes & $\begin{array}{l}\text { MRA showing no recur- } \\
\text { rence at } 5 \text { mos }\end{array}$ & 0 \\
\hline
\end{tabular}

CTA = CT angiography; DSA = digital subtraction angiography; MRA = MR angiography; NA = not applicable; PS = pseudoaneurysm.

which was retreated with coiling and PED placement. PED placement was technically successful in all 4 cases. In 3 cases, 1 PED was used. In 1 case, 2 PEDs were used because of a persistent flow jet in the pseudoaneurysm sac following placement of the first PED. All 3 pseudoaneurysms were successfully obliterated after PED deployment. In the case of vessel laceration, there was persistent extravasation after PED placement, and the vessel was endovascularly occluded using coils. This patient had persistent perfusion-related weakness corresponding to the occluded ICA and underwent successful superficial temporal artery to middle cerebral artery bypass 1 month later with subsequent improvement of symptoms. All patients had a good clinical outcome (mRS score of 0 or 1). Procedural and outcome data are summarized in Table 2.

\section{Illustrative Case 1}

An 18-year-old woman with a pineal region mass underwent endoscopic biopsy and third ventriculostomy. Biopsy of the mass was uneventful. During attempted third ventriculostomy, electrocautery of the floor of the third ventricle was associated with significant bleeding. Following copious irrigation, the bleeding appeared to have stopped. Intraoperative MRI did not demonstrate any obvious vascular injury. The procedure was aborted, and the patient was transferred to the angiography suite for emergency cerebral angiography. Angiography did not demonstrate any evidence of pseudoaneurysm, vessel perforation, or dissection. A 2-week follow-up angiogram demonstrated a 5-mm basilar apex pseudoaneurysm at the origin of the right posterior cerebral artery (Fig. 1A). This was treated with endovascular coiling followed by placement of a 2.5 $\times 17-\mathrm{mm}$ LVIS Jr. stent (MicroVention). Postprocedure angiography confirmed no filling of the aneurysm and patency of the stent in the parent vessel (Fig. 1B).

Two-month follow-up MR angiography demonstrated a 3-mm aneurysm recurrence, which was confirmed with cerebral angiography (Fig. 1C). The recurrent pseudoaneurysm was treated with recoiling followed by placement of a $2.75 \times 14-\mathrm{mm}$ Pipeline Flex stent (Medtronic) placed within the LVIS Jr. stent. Postprocedure angiography demonstrated contrast stasis within the recurrent aneurysm, and rotational angiography (DynaCT, Siemens) demonstrated excellent apposition of the stent to the vessel wall (Fig. 2). Follow-up angiograms obtained 4 and 12 months later confirmed no residual pseudoaneurysm filling and continued patency of the stents (Fig. 3). The patient's mRS score at follow-up was 0 .

\section{Illustrative Case 2}

A 61-year-old woman with a history of a benign pituitary macroadenoma who presented with nasal obstruction
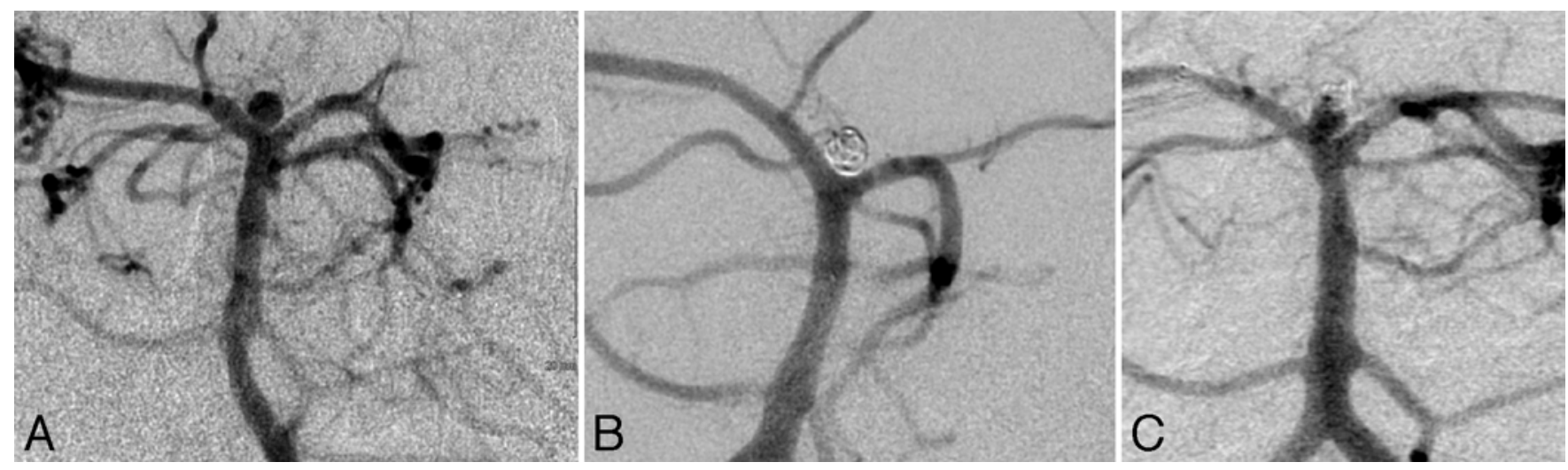

FIG. 1. Illustrative Case 1. High-magnification oblique cerebral angiograms. A: Angiogram demonstrating a pseudoaneurysm at the junction of the basilar apex and the right posterior cerebral artery. B: Angiogram obtained after stent-assisted coiling showing no evidence of residual aneurysm filling. C: Angiogram obtained 1 month after stent coiling showing irregular large recurrence of the pseudoaneurysm. The right posterior cerebral artery stent remains widely patent. 

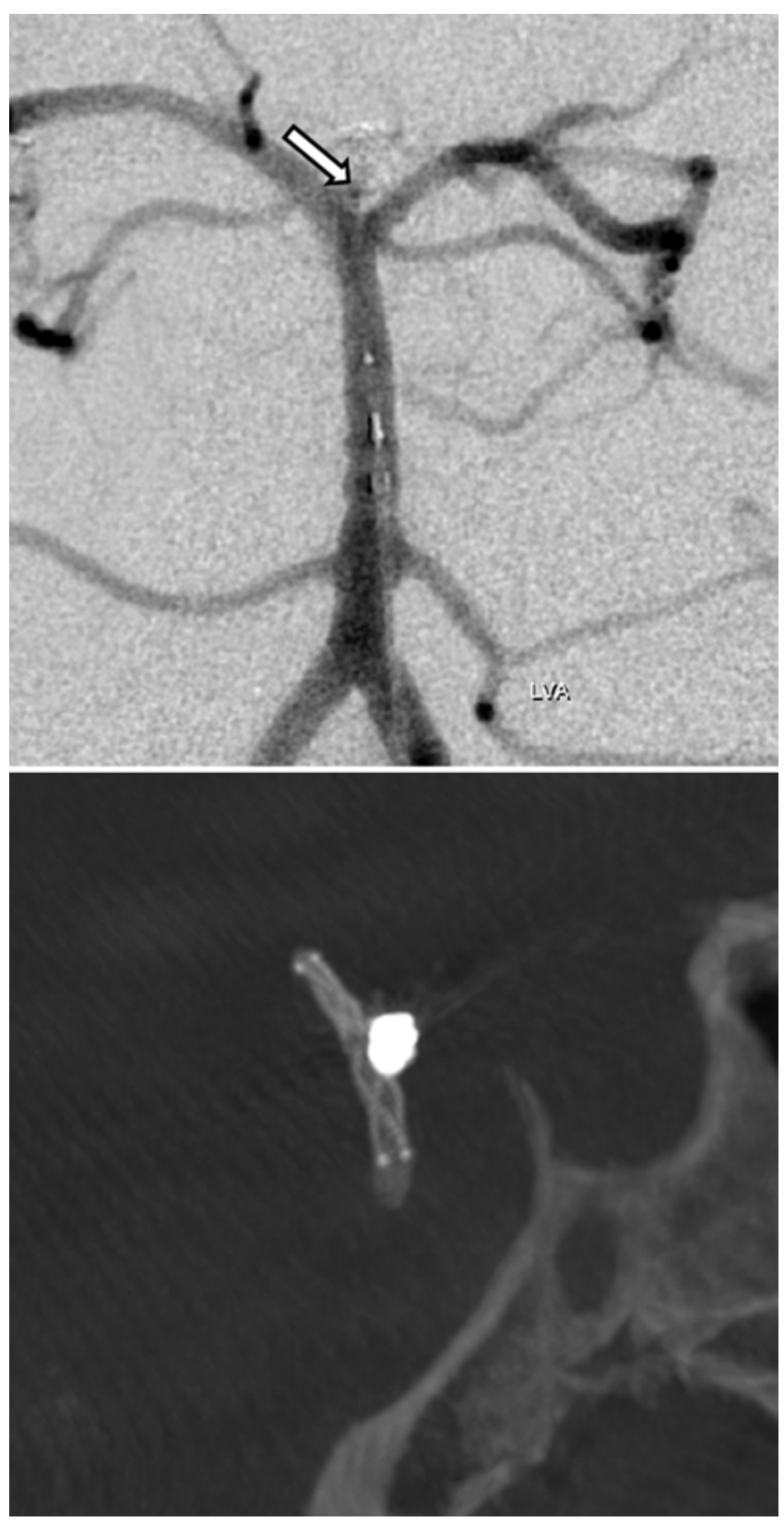

FIG. 2. Illustrative Case 1. Upper: Anteroposterior cerebral angiogram obtained after recoiling and placement of a PED showing contrast stasis at the aneurysm neck (arrow). Lower: Rotational angiogram (DynaCT) obtained after PED placement and coiling, demonstrating good apposition of the stent to the vessel wall and excellent packing of the coil mass within the aneurysm sac.

was found to have a mass centered in the sphenoid sinus. Needle biopsy demonstrated recurrent pituitary macroadenoma, and she was thus referred for operative evaluation. A combined endoscopic/microsurgical approach with otolaryngology was used for tumor resection. There was a significant amount of scar tissue in the sphenoid sinus. After tumor was removed from the sphenoid sinus, the right optic nerve was identified, and a small amount of tumor from the right inferior margin of the field was scraped using a ring curette. Subsequently, brisk bleeding was en-

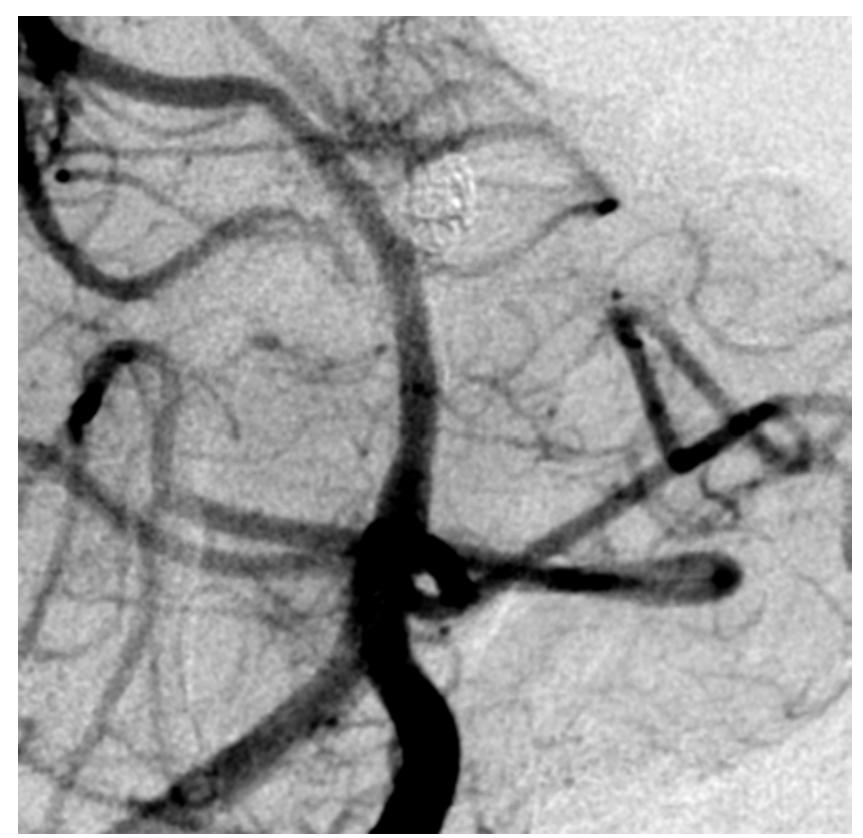

FIG. 3. Illustrative Case 1. High-magnification oblique cerebral angiogram obtained at 12-month follow-up demonstrating complete occlusion of the pseudoaneurysm with no evidence of residual or recurrent aneurysm filling. The stents within the right posterior cerebral artery (PCA) remain widely patent. The left PCA appears small in caliber, but there is a large posterior communicating artery on the left side and there is diversion away from this vessel giving the impression of a diminutive left $P_{1}$ segment.

countered from the right ICA. The cavity was packed and the patient was taken for emergency cerebral angiography, which demonstrated disintegration of the right ICA at the distal cavernous segment proximal to the anterior genu with contrast extravasation and injury to the intima with narrowing and dissection of the vessel (Fig. 4).

A PED was placed was placed proximal to the ophthalmic artery to the distal petrous segment; however, there was suboptimal wall apposition and continued extravasation from the segment (Fig. 5), likely because of the nature and size of the vessel injury. The vessel was sacrificed using coil embolization with trapping of the injured segment with coils from proximal to the ophthalmic artery to the distal petrous segment. There was no further flow through the right ICA, with intact filling of the right ophthalmic artery and supraclinoid ICA from extracranial collaterals and cross-filling from the left anterior cerebral artery via the anterior communicating artery (Fig. 6). The patient had continued signs of right-sided ischemia, and CT perfusion imaging indicated a perfusion deficit. She underwent a right superficial temporal artery to middle cerebral artery bypass 1 month later, which restored flow through the right hemisphere.

\section{Discussion}

Iatrogenic injury of the intracranial vasculature is a rare but highly morbid surgical complication. Injuries of the intracranial ICA during surgery involving the sellar region are well documented in the literature. ${ }^{515}$ Cases of 


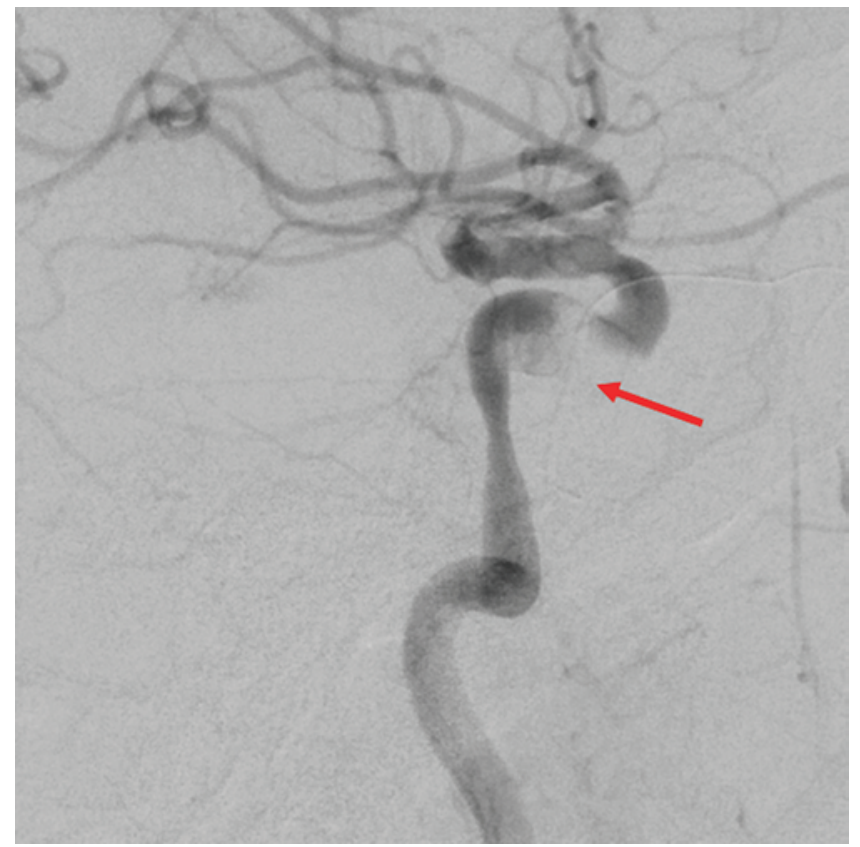

FIG. 4. Illustrative Case 2. High-magnification oblique cerebral angiogram demonstrating an injury to the cavernous segment of the right ICA with active extravasation (arrow).

iatrogenic injury of the basilar artery, anterior cerebral artery, posterior cerebral artery, and middle cerebral artery occur less commonly but have also been reported. . $^{4,10,12,18}$ Recently, the use of flow-diverting stents has been reported in the treatment of iatrogenic intracranial vascular injuries. Nerva et al..$^{13}$ presented 2 cases in which pseudoaneurysms were encountered following transsphenoidal pituitary tumor resection. One patient was treated on postinjury Day 4 with coil embolization and PED placement with complete aneurysm occlusion. The other patient was treated approximately 2 weeks after injury with telescoping PEDs. Both patients had angiographic resolution of their pseudoaneurysms. Similarly, Amenta et al. ${ }^{2}$ reported a case of an iatrogenic ICA pseudoaneurysm that was successfully treated with telescoping PEDs. Sylvester et al. ${ }^{17}$ presented 2 cases of transsphenoidal pituitary tumor resection with vessel injury treated with PEDs. In both cases, iatrogenic pseudoaneurysms were treated successfully with PEDs without complications, and the patients had good clinical outcomes. Our experience mirrors these results, as all 3 pseudoaneurysm cases we encountered were successfully treated with PED placement. One of our cases was initially treated with stent-assisted coiling. In this case, we elected to not primarily attempt PED placement out of concern for covering perforator vessels originating off the basilar and posterior cerebral arteries and the inability to pretreat with antiplatelet agents. Following pseudoaneurysm recurrence, we believed that further coiling and PED placement was the best remaining treatment option. During the initial evaluation of this patient, it was thought that the greater metallic coverage of the LVIS Jr. stent might allow for some improved flow-diverting properties compared with more traditional stents such as the Neuroform device (Stryker). Therefore, we implanted the LVIS Jr. and placed coils within the pseudoaneurysm. Based on this recurrence, it is apparent that the LVIS Jr. does not provide sufficient flow diversion in the treatment of pseudoaneurysms, and PED placement should be a primary consideration.

One patient in our series experienced frank vessel disruption during surgery, which was confirmed on immediate postsurgical angiography. PED placement was unsuccessful in attenuating extravasation in this case, and the vessel was endovascularly occluded following confirmation of robust cross-fill through the anterior communicating artery. Other authors have hypothesized that the PED is unable to cure vessel injuries with ongoing extravasation because of a persistent pressure gradient from the intravascular to extravascular space across the injury. ${ }^{1}$ Our case lends credence to this hypothesis and supports attempting alternative measures of vessel reconstruction, such as covered stent placement. ${ }^{7}$ Shakir et al. ${ }^{16}$ reported a case of frank vessel disruption that was treated with a covered stent followed by PED. The authors used 2 PEDs as a secondary therapy to treat a Type 1 endoleak following placement of the covered stent. In our case, we believed that tortuous anatomy at the location of the injury would be prohibitive to adequate wall apposition of the covered stent to the vessel laceration, a shortcoming that has been reported previously. ${ }^{7}$

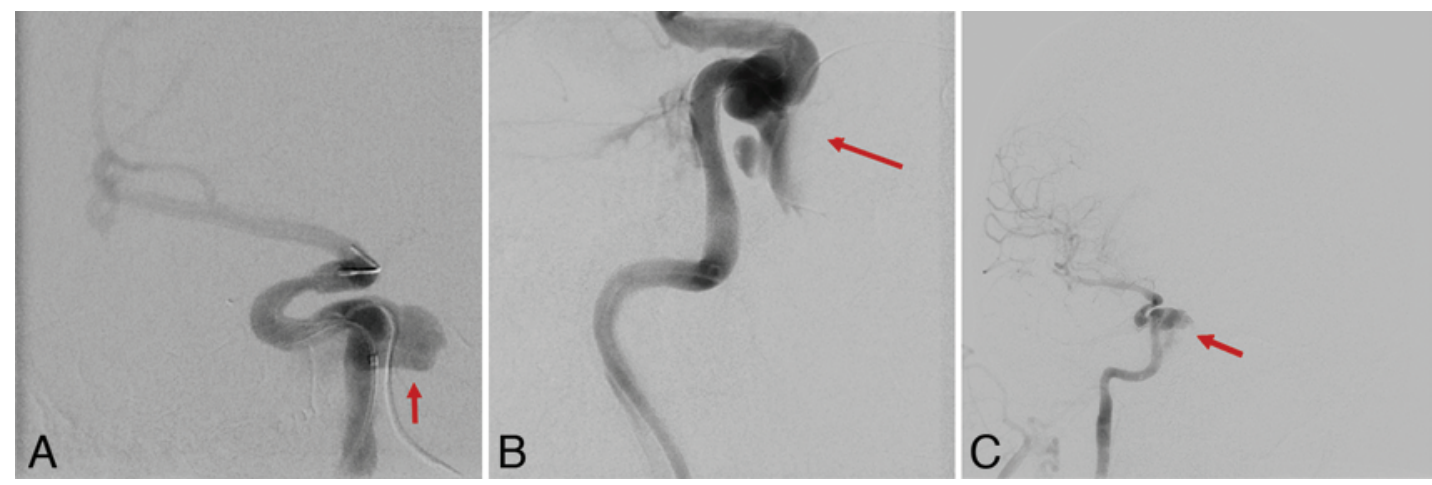

FIG. 5. Illustrative Case 2. A: Lateral cerebral angiogram demonstrating the right ICA following PED placement with suboptimal wall apposition. B and C: Oblique (B) and anteroposterior projection (C) cerebral angiograms demonstrating active contrast extravasation (arrow) following PED placement. 


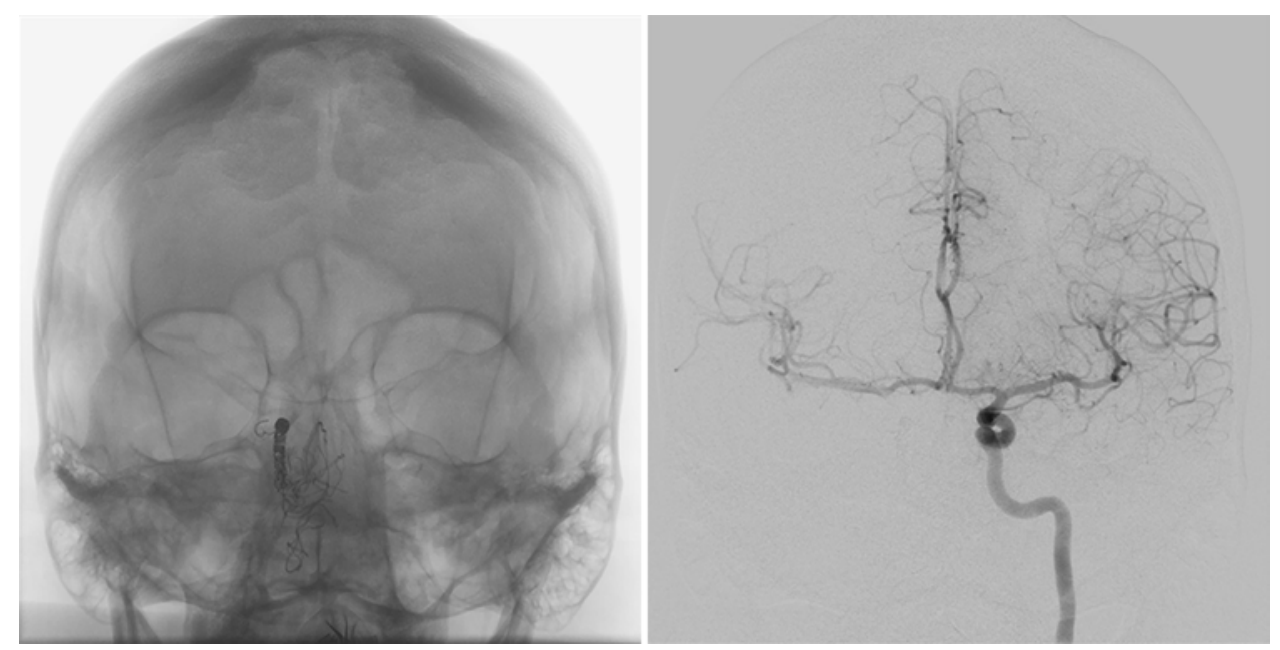

FIG. 6. Illustrative Case 2. Anteroposterior projection angiogram (native image, left) and digital subtraction angiogram (right) obtained following coil embolization of the right ICA. The subtracted image demonstrates adequate cross-filling of the right middle cerebral artery and anterior cerebral artery via the anterior communicating artery.

Our series underscores the need for short-term followup angiography if immediate postoperative angiography is unrevealing. In 2 of our cases, an initial angiogram was negative despite the operative surgeon's high degree of suspicion of a large vessel injury. Both of these patients demonstrated pseudoaneurysm formation on short-term follow-up angiography. Other authors have postulated that the initial false-negative angiogram is a result of cerebral vasospasm causing decreased flow in the parent vessel and apposition of the walls of the aneurysm neck, precluding aneurysm filling. ${ }^{8}, 12$ Some have attributed this phenomenon to aneurysm thrombosis with later recanalization. ${ }^{12,19}$ The timing of follow-up angiography is debatable, but significant delays should be avoided because of the propensity of pseudoaneurysms to rapidly enlarge and rupture..$^{14}$

\section{Conclusions}

The use of the PED is feasible in the management of iatrogenic pseudoaneurysms of the intracranial vasculature. In cases of frank vessel perforation, an alternative strategy such as covered stent placement should be considered. Endovascular or surgical vessel occlusion remains the definitive treatment in cases of refractory hemorrhage. Short-term follow-up angiography should be performed in cases with negative immediate postprocedural angiography, as vessel injuries can remain occult in the immediate postoperative period.

\section{References}

1. Ambekar S, Sharma M, Smith D, Cuellar H: Successful treatment of iatrogenic vertebral pseudoaneurysm using pipeline embolization device. Case Rep Vasc Med 2014:341748, 2014

2. Amenta PS, Starke RM, Jabbour PM, Tjoumakaris SI, Gonzalez LF, Rosenwasser RH, et al: Successful treatment of a traumatic carotid pseudoaneurysm with the Pipeline stent: case report and review of the literature. Surg Neurol Int 3:160, 2012

3. Becske T, Kallmes DF, Saatci I, McDougall CG, Szikora I, Lanzino G, et al: Pipeline for uncoilable or failed aneurysms: results from a multicenter clinical trial. Radiology 267:858868,2013

4. Ciceri EF, Regna-Gladin C, Erbetta A, Chiapparini L, Nappini $\mathrm{S}$, Savoiardo $\mathrm{M}$, et al: Iatrogenic intracranial pseudoaneurysms: neuroradiological and therapeutical considerations, including endovascular options. Neurol Sci 27:317-322, 2006

5. Ciric I, Ragin A, Baumgartner C, Pierce D: Complications of transsphenoidal surgery: results of a national survey, review of the literature, and personal experience. Neurosurgery 40:225-237, 1997

6. Fiorella D, Lylyk P, Szikora I, Kelly ME, Albuquerque FC, McDougall CG, et al: Curative cerebrovascular reconstruction with the Pipeline embolization device: the emergence of definitive endovascular therapy for intracranial aneurysms. J Neurointerv Surg 1:56-65, 2009

7. Griauzde J, Gemmete JJ, Pandey AS, McKean EL, Sullivan SE, Chaudhary N: Emergency reconstructive endovascular management of intraoperative complications involving the internal carotid artery from trans-sphenoidal surgery. J Neurointerv Surg 7:67-71, 2015

8. Kaim A, Proske M, Kirsch E, von Weymarn A, Radü EW, Steinbrich W: Value of repeat-angiography in cases of unexplained subarachnoid hemorrhage (SAH). Acta Neurol Scand 93:366-373, 1996

9. Lee CH, Chen SM, Lui TN: Posterior cerebral artery pseudoaneurysm, a rare complication of pituitary tumor transsphenoidal surgery: case report and literature review. World Neurosurg 84:1493.e1-1493.e3, 2015

10. McLaughlin MR, Wahlig JB, Kaufmann AM, Albright AL: Traumatic basilar aneurysm after endoscopic third ventriculostomy: case report. Neurosurgery 41:1400-1404, 1997

11. Medel R, Crowley RW, Hamilton DK, Dumont AS: Endovascular obliteration of an intracranial pseudoaneurysm: the utility of Onyx. J Neurosurg Pediatr 4:445-448, 2009

12. Munich SA, Cress MC, Rangel-Castilla L, Krishna C, Siddiqui AH, Snyder KV: Importance of repeat angiography in the diagnosis of iatrogenic anterior cerebral artery territory pseudoaneurysm following endoscopic sinus surgery. J Neurointerv Surg 8:e20, 2016

13. Nerva JD, Morton RP, Levitt MR, Osbun JW, Ferreira MJ, Ghodke BV, et al: Pipeline Embolization Device as primary treatment for blister aneurysms and iatrogenic pseudoaneurysms of the internal carotid artery. J Neurointerv Surg 7:210-216, 2015 
14. Parkinson D, West M: Traumatic intracranial aneurysms. J Neurosurg 52:11-20, 1980

15. Raymond J, Hardy J, Czepko R, Roy D: Arterial injuries in transsphenoidal surgery for pituitary adenoma; the role of angiography and endovascular treatment. AJNR Am J Neuroradiol 18: 655-665, 1997

16. Shakir HJ, Garson AD, Sorkin GC, Mokin M, Eller JL, Dumont TM, et al: Combined use of covered stent and flow diversion to seal iatrogenic carotid injury with vessel preservation during transsphenoidal endoscopic resection of clival tumor. Surg Neurol Int 5:81, 2014

17. Sylvester PT, Moran CJ, Derdeyn CP, Cross DT, Dacey RG, Zipfel GJ, et al: Endovascular management of internal carotid artery injuries secondary to endonasal surgery: case series and review of the literature. J Neurosurg 125:1256-1276, 2016

18. Tokunaga K, Kusaka N, Nakashima H, Date I, Ohmoto T: Coil embolization of intradural pseudoaneurysms caused by arterial injury during surgery: report of two cases. AJNR Am J Neuroradiol 22:35-39, 2001

19. Valle EP, Tamargo RJ, Gailloud P: Thrombosis and subsequent recanalization of a ruptured intracranial aneurysm in 2 children, demonstrating the value of repeating catheter angiography after an initial negative study. J Neurosurg Pediatr 5:346-349, 2010
20. Walcott BP, Stapleton CJ, Choudhri O, Patel AB: Flow diversion for the treatment of intracranial aneurysms. JAMA Neurol 73:1002-1008, 2016

21. Wendl CM, Henkes H, Martinez Moreno R, Ganslandt O, Bäzner H, Aguilar Pérez M: Direct carotid cavernous sinus fistulae: vessel reconstruction using flow-diverting implants. Clin Neuroradiol [epub ahead of print], 2016

\section{Disclosures}

Dr. Taussky reports a consultant relationship with Medtronic.

\section{Author Contributions}

Conception and design: Griauzde, Ravindra. Acquisition of data: Griauzde, Ravindra, Mazur. Analysis and interpretation of data: Griauzde. Drafting the article: Griauzde, Ravindra. Critically revising the article: all authors. Reviewed submitted version of manuscript: all authors. Approved the final version of the manuscript on behalf of all authors: Pandey.

\section{Correspondence}

Aditya S. Pandey, Department of Neurosurgery, University of Michigan, 1500 E Medical Center Dr., Rm. 3552TC, Ann Arbor, MI 48109-5338. email: adityap@med.umich.edu. 